Supporting Information

\title{
Multimechanism Physical Cross-Linking Results in Tough and Self- Healing Hydrogels for Various Applications
}

\author{
Wei Cui, ${ }^{\mathrm{a}, 1}$ Meng-han Pi, ${ }^{\mathrm{a}}$ Yue-shan Li, ${ }^{\mathrm{a}}$ Ling-Ying Shi, ${ }^{\mathrm{a}}$ and Rong Ran ${ }^{\mathrm{a}, *}$ \\ ${ }^{\mathrm{a} C o l l e g e ~ o f ~ P o l y m e r ~ S c i e n c e ~ a n d ~ E n g i n e e r i n g, ~ S t a t e ~ K e y ~ L a b o r a t o r y ~ o f ~ P o l y m e r ~ M a t e r i a l s ~}$ \\ Engineering, Sichuan University, Chengdu, 610065, China
}

*Corresponding author. Email address: ranrong@scu.edu.cn

Tel: +86-28-85462890, Fax: +86-28-85462890

1: Present address

W. Cui: Graduate School of Life Science, Hokkaido University, Sapporo, 001-0021, Japan. 

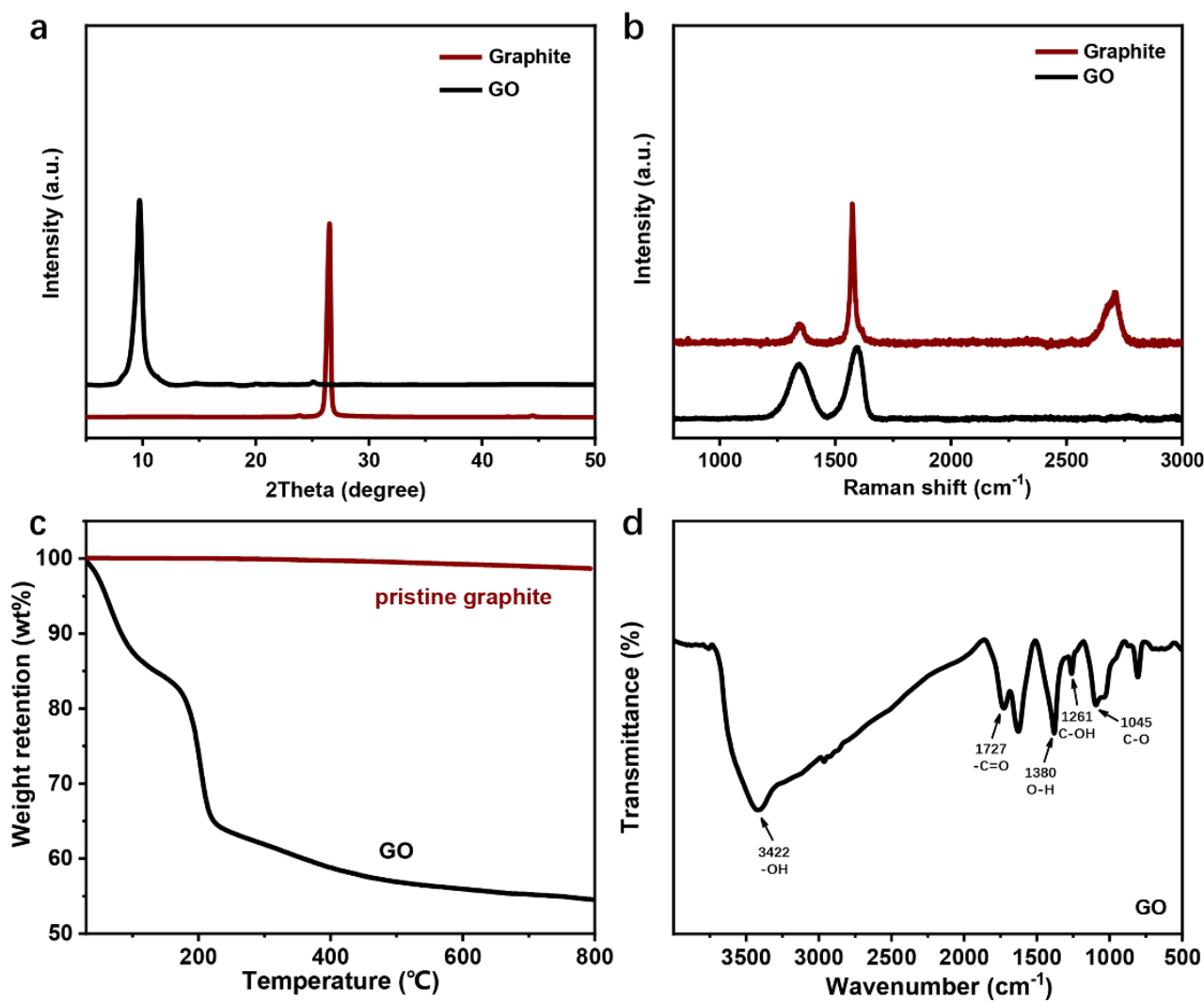

Figure S1. Characterizations of pristine graphite and prepared graphene oxide (GO). (a) XRD patterns, (b) Raman spectra, and (c) TGA curves of pristine graphite and GO. (d) FTIR spectrum of GO. The characterizations show that abundant oxygen functional groups are generated on the surface of GO, which are conducive to the generation of hydrogen bonding between polymer chains and GO. 

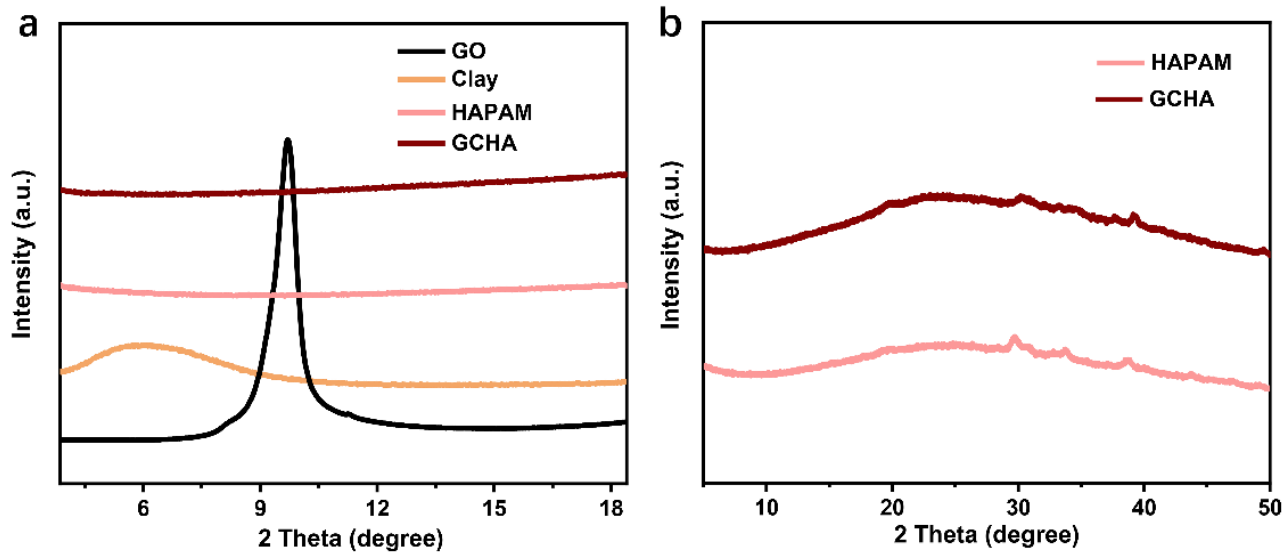

Figure S2. (a) XRD profiles of GO, clay, HAPAM and GCHA gels at 2 theta scale from $2^{\circ}$ to $18.5^{\circ}$. (b) XRD patterns of HAPAM and GCHA gels at 2 theta scale from $5^{\circ}$ to $50^{\circ}$. 

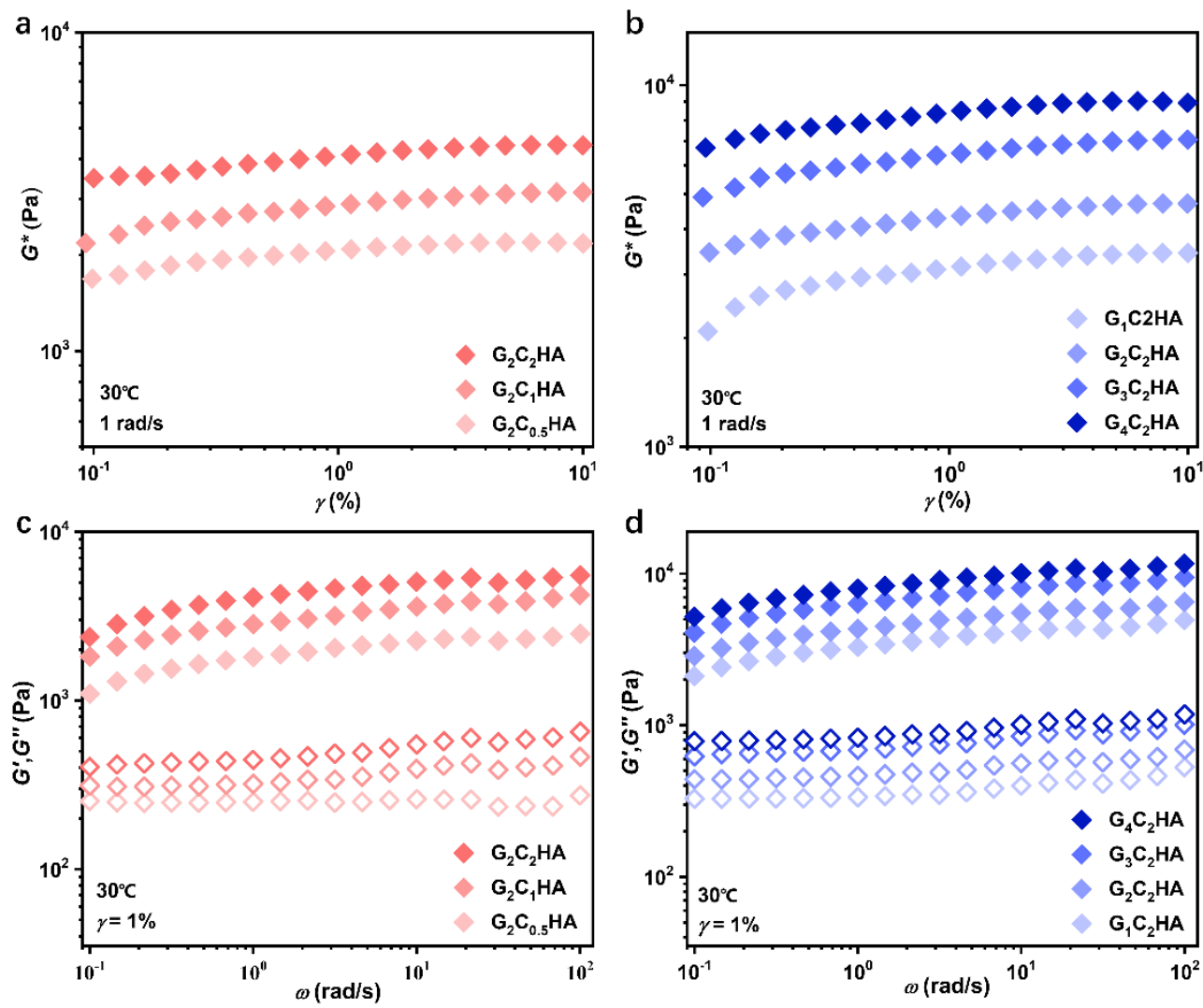

Figure S3. Rheological properties of GCHA hydrogels containing varied nanosheet content. Strain $\gamma$ dependence of complex modulus $G^{*}$ for $\mathrm{G}_{\mathrm{m}} \mathrm{C}_{2} \mathrm{HA}$ gels (a) with fixed clay but varied $\mathrm{GO}$ content, and $\mathrm{G}_{2} \mathrm{C}_{\mathrm{n}} \mathrm{HA}$ gels with fixed $\mathrm{GO}$ but varied clay content with (b) at $30^{\circ} \mathrm{C}$ and $\omega=1 \mathrm{rad} \mathrm{s}^{-1}$. Angular frequency $\omega$ dependence of storage modulus $G^{\prime}$ (solid symbols) and loss modulus $G^{\prime \prime}$ (hollow symbols) for $\mathrm{G}_{\mathrm{m}} \mathrm{C}_{2} \mathrm{HA}$ gels (c), and $\mathrm{G}_{2} \mathrm{C}_{\mathrm{n}} \mathrm{HA}$ gels (d) at $30^{\circ} \mathrm{C}$. 

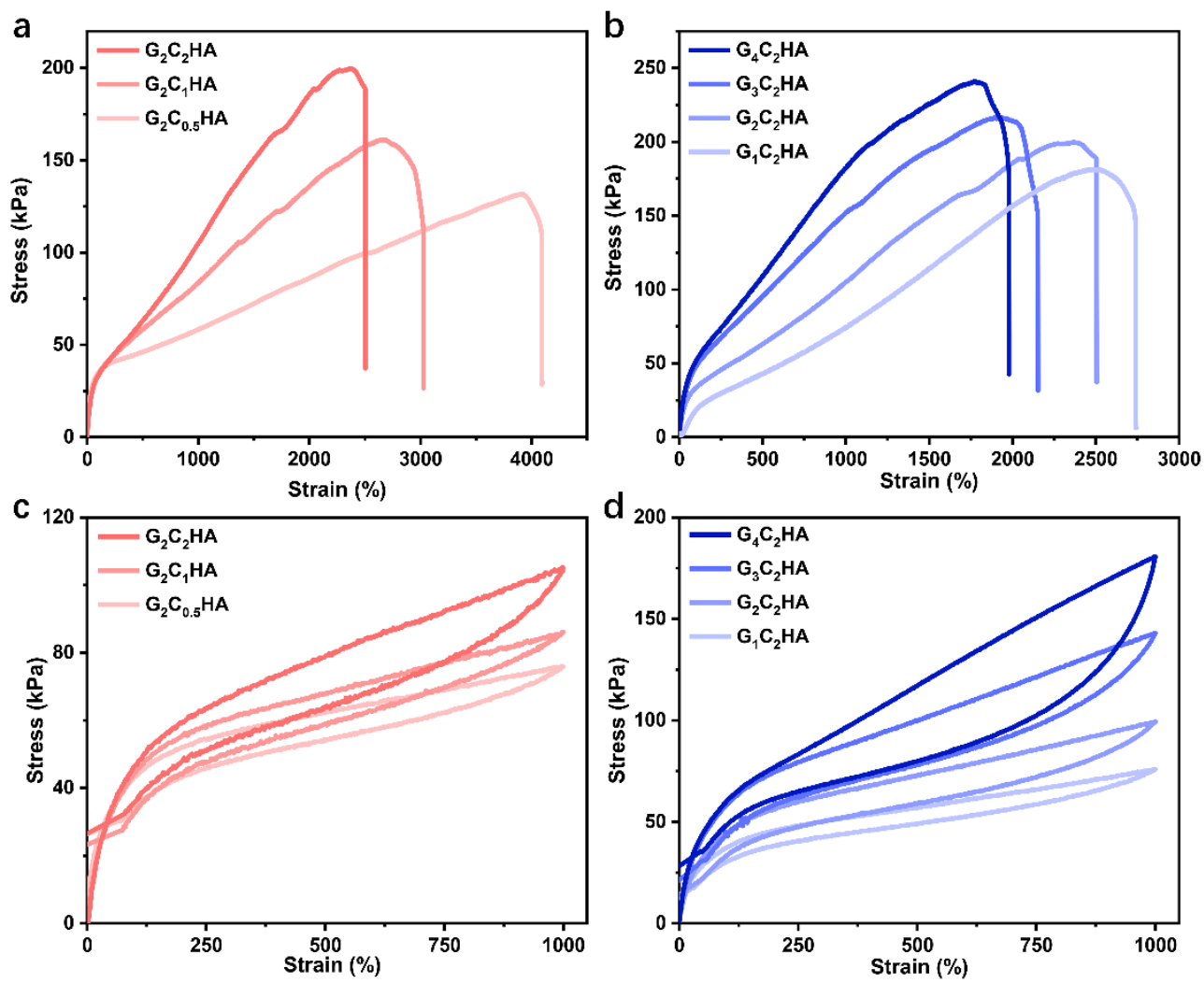

Figure S4. Mechanical properties of GCHA gels containing varied nanosheet content. (a) Tensile and (c) loading-unloading stress-strain curves of $\mathrm{G}_{\mathrm{m}} \mathrm{C}_{2} \mathrm{HA}$ gels with fixed clay but different $\mathrm{GO}$ content. (b) Tensile and (d) loading-unloading stress-strain curves of $\mathrm{G}_{2} \mathrm{C}_{\mathrm{n}} \mathrm{HA}$ gels with fixed $\mathrm{GO}$ but different clay content. 

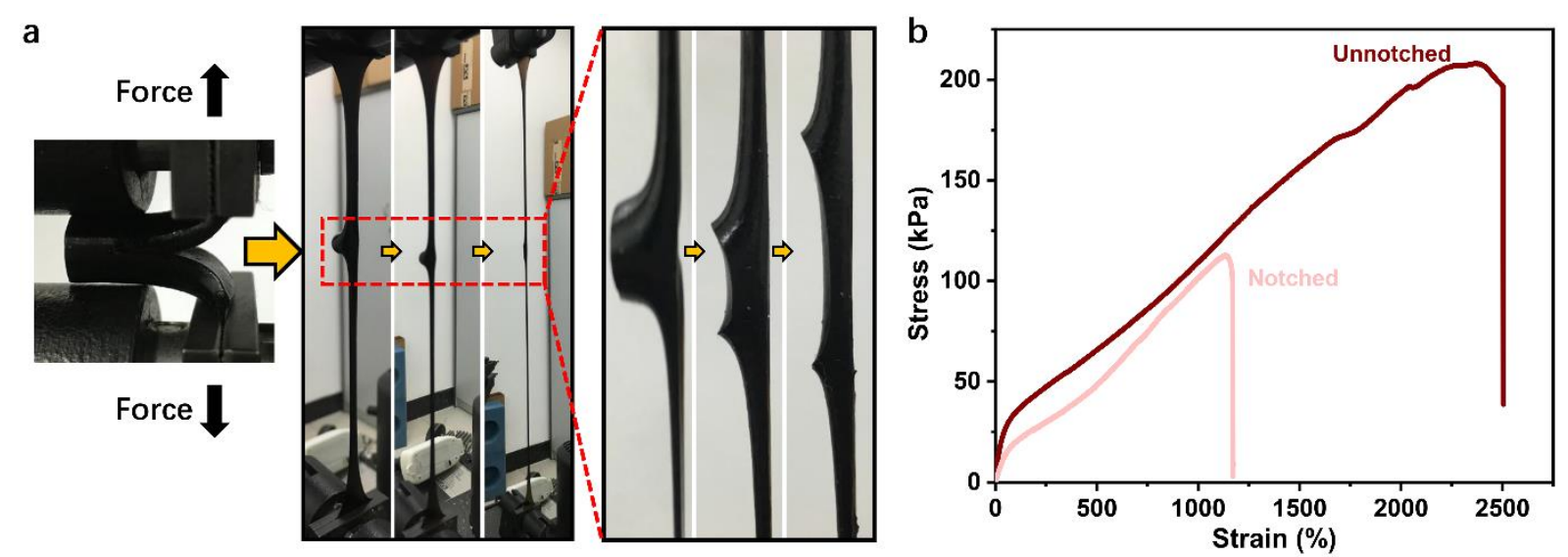

Figure S5. Superior tearing resistance of the GCHA gels. (a) Photographs of the GCHA gel during trouser tearing test, the crack gradually becomes blunt as the two legs of the sample displace. (b) Tensile stress-strain curves of unnotched and notched GCHA gels. 


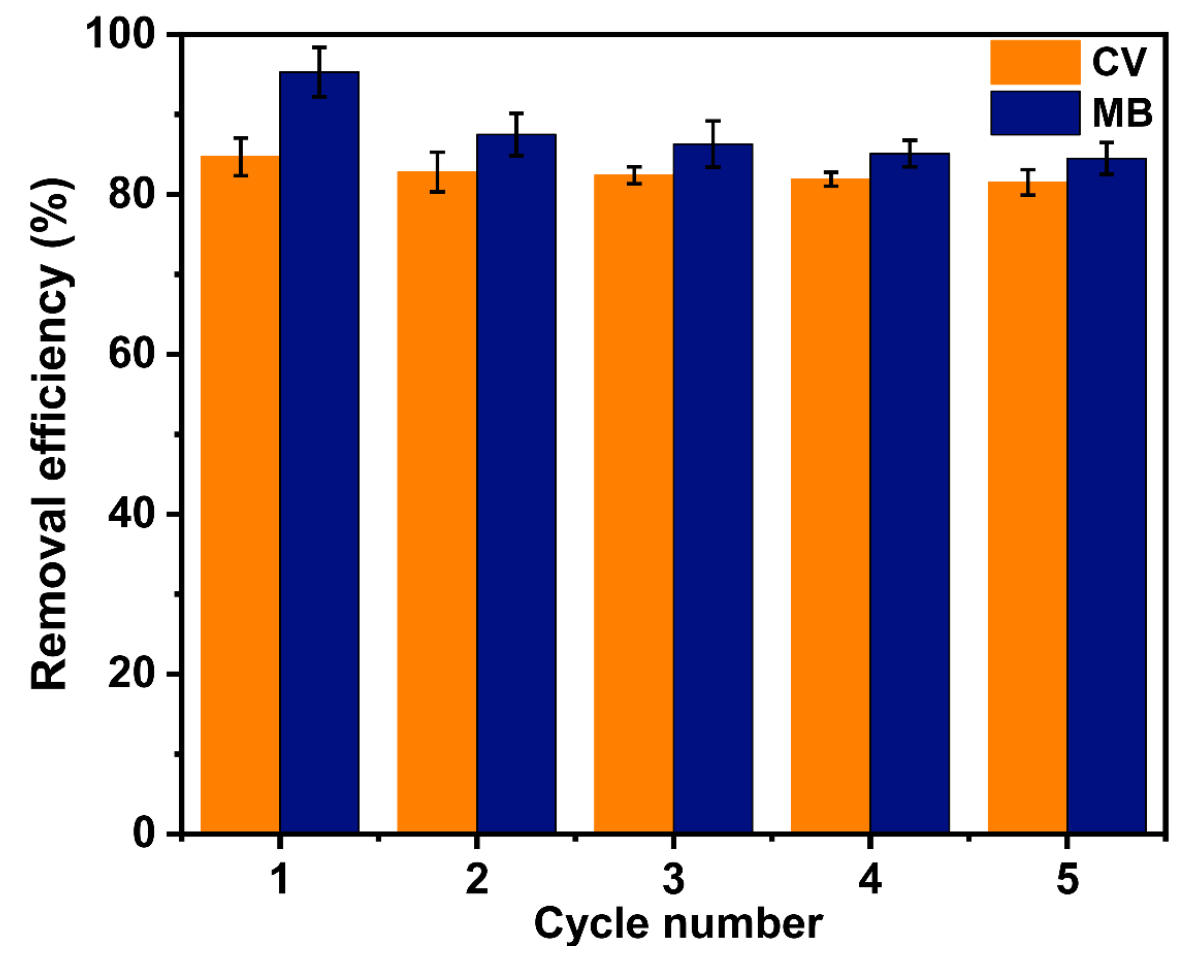

Figure S6. The removal efficiency of the GCHA gels on two cationic dyes, CV and MB, after each cycle of adsorption. The removal efficiency is defined by comparing the dye concentration in the solution before and after adsorption for each cycle. 